\title{
Non-invasive surveillance of Plasmodium infection by real-time PCR analysis of ethanol preserved faeces from Ugandan school children with intestinal schistosomiasis
}

\author{
Hajri Al-Shehri ${ }^{1,2}$, B. Joanne Power ${ }^{3}$, John Archer ${ }^{1}$, Alice Cousins' ${ }^{1}$, Aaron Atuhaire ${ }^{4}$, Moses Adriko ${ }^{4}$, \\ Moses Arinaitwe ${ }^{4}$, Abdullah D. Alanazi ${ }^{5}$, E. James LaCourse ${ }^{1}$, Narcis B. Kabatereine ${ }^{4}$ and J. Russell Stothard ${ }^{1 *}$ (D)
}

\begin{abstract}
Background: As part of ongoing co-surveillance of intestinal schistosomiasis and malaria in Ugandan school children, a non-invasive detection method for amplification of Plasmodium DNA using real-time (rt)PCR analysis of ethanol preserved faeces (EPF) was assessed. For diagnostic tabulations, results were compared to rtPCR analysis of dried blood spots (DBS) and field-based point-of-care (POC) rapid diagnostic tests (RDTs).

Methods: A total of 247 school children from 5 primary schools along the shoreline of Lake Albert were examined with matched EPF and DBS obtained. Mean prevalence and prevalence by school was calculated by detection of Plasmodium DNA by rtPCR using a $18 \mathrm{~S}$ rDNA Taqman ${ }^{\circledR}$ probe. Diagnostic sensitivity, specificity, positive and negative predictive values were tabulated and compared against RDTs.

Results: By rtPCR of EPF and DBS, 158 (63.9\%; 95\% Cl 57.8-69.7) and 198 (80.1\%, 95\% Cl 74.7-84.6) children were positive for Plasmodium spp. By RDT, 138 (55.8\%; 95\% Cl 49.6-61.9) and 45 (18.2\%; 95\% Cl 13.9-23.5) children were positive for Plasmodium falciparum, and with non-P. falciparum co-infections, respectively. Using RDT results as a convenient field-based reference, the sensitivity of rtPCR of EPF and DBS was 73.1\% (95\% Cl 65.2-79.8) and 94.2\% (95\% Cl 88.9-97.0) while specificity was 47.7\% (95\% Cl 38.5-57.0) and 37.6\% (95\% Cl 29.0-46.9), respectively. With one exception, school prevalence estimated by analysis of EPF was higher than that by RDT. Positive and negative predictive values were compared and discussed.

Conclusions: In this high transmission setting, EPF sampling with rtPCR analysis has satisfactory diagnostic performance in estimation of mean prevalence and prevalence by school upon direct comparison with POC-RDTs. Although analysis of EPF was judged inferior to that of DBS, it permits an alternative non-invasive sampling regime that could be implemented alongside general monitoring and surveillance for other faecal parasites. EPF analysis may also have future value in passive surveillance of low transmission settings.
\end{abstract}

Keywords: Plasmodium, Schistosoma mansoni, Real-time PCR, Surveillance, RDT, Faecal sampling

\section{Background}

Malaria continues to be a public health problem in 90 countries worldwide [1], with the impact of global

\footnotetext{
${ }^{*}$ Correspondence: russell.stothard@lstmed.ac.uk

1 Department of Tropical Disease Biology, Liverpool School of Tropical Medicine, Liverpool L3 5QA, UK

Full list of author information is available at the end of the article
}

control flat-lining over the past 2 years; the greatest disease burden remains in sub-Saharan Africa (SSA) where over $90 \%$ of deaths occur [2]. Here, weak health systems with restricted diagnostic repertoires and inadequate access to prompt treatment preside, alongside favorable conditions for Plasmodium transmission [2, 3]. Collectively, this places certain demographical groups, e.g.

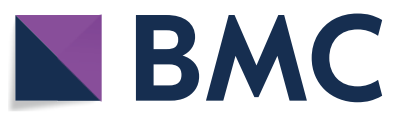

(C) The Author(s) 2019. This article is distributed under the terms of the Creative Commons Attribution 4.0 International License (http://creativecommons.org/licenses/by/4.0/), which permits unrestricted use, distribution, and reproduction in any medium, provided you give appropriate credit to the original author(s) and the source, provide a link to the Creative Commons license, and indicate if changes were made. The Creative Commons Public Domain Dedication waiver (http://creativecommons.org/ publicdomain/zero/1.0/) applies to the data made available in this article, unless otherwise stated. 
infants, more vulnerable than others [4] although infection prevalence and non-severe disease in other groups, such school children, should not be overlooked [4-6]. A broader appraisal of infection surveillance is needed, especially in the future context of gaining transmission control and unveiling the importance of asymptomatic carriage [7-9]. Indeed, with introduction of more sensitive diagnostics, over and above what current rapid diagnostic tests (RDTs) can provide, our understanding of the environmental importance of asymptomatics will change [10]. Exploration of non-invasive sampling, e.g. collection of saliva or urine, for detection of Plasmodium DNA has been explored but as of yet is not routinely used $[7,11$, 12].

In Uganda, for example, control of malaria is a major public health challenge [13], especially in young children [6]. The geographical distribution of malaria also aligns with other mosquito-borne diseases such as lymphatic filariasis, making co-surveillance with neglected tropical diseases justifiable [14]. On the Lake Albert shoreline, however, intestinal schistosomiasis is hyperendemic [15] and ongoing school-based preventive chemotherapy control has taken place, with periodic disease surveillance, over the last 15 years $[16,17]$. The local prevalence of Plasmodium falciparum in mothers and pre-school-aged children is very high [18-20], with non-P. falciparum infections also reported [21] but the prevalence of infection in school children rarely measured [22]. As part of ongoing surveillance of intestinal schistosomiasis in this area, Al-Shehri et al. [15] revealed that over half of the sampled school children harboured RDT positive asymptomatic infections, a quarter being anaemic $(<115 \mathrm{~g} / \mathrm{L})$ and $11 \%$ had faecal occult blood in stool. The local prevalence of egg-patent intestinal schistosomiasis was $46.5 \%$, ranging in excess of $80 \%$ in certain schools along the immediate shoreline [15].

Point-of-care (POC) and reference laboratory diagnostics tests play a critical role in monitoring and surveillance of disease control programmes, yet finding synergies for integrated surveillance is limited [23]. Indeed, current siloing of diseases and infection detection is unfortunate for there could be opportunities, where appropriate, to share programmatic costs and intervention repertoires for intestinal schistosomiasis and malaria $[13,24]$. Faecal samples are widely collected for surveillance of intestinal schistosomiasis but have not been fully exploited to co-detect malaria, for example, by real-time PCR (rtPCR) analysis for Plasmodium DNA [25-27]. By contrast, non-invasive faecal sampling has burgeoned the detection of Plasmodium DNA in non-human primates, developing our epidemiological understanding of natural and zoonotic malaria immensely [28-31].
This study sought to investigate whether rtPCR analysis of extracted DNA from ethanol preserved faeces (EPF), collected during routine surveillance for intestinal schistosomiasis, could be informative for population surveillance of Plasmodium infection in school children.

\section{Methods \\ Study area}

In this cross-sectional survey, field sampling and examinations of children took place during May 2015 in five primary schools in Buliisa District located within the Lake Albert region. Three of these five schools have been visited previously as sentinel surveillance sites of the national control programme [32] and the global positioning system (GPS) coordinates for each school were recorded: Walakuba (GPS $01^{\circ} 50.323 \mathrm{~N}, 031^{\circ} 22.740 \mathrm{E}$ ), Bugoigo (GPS $01^{\circ} 54.004 \mathrm{~N}, 031^{\circ} 24.750 \mathrm{E}$ ) and Runga (GPS $01^{\circ} 43.828 \mathrm{~N}, 031^{\circ} 18.603 \mathrm{E}$ ) were located on the immediate shoreline at an approximate altitude of $615 \mathrm{~m}$ on average above sea level, while Biiso (GPS $01^{\circ}$ $45.516 \mathrm{~N}, 031^{\circ} 25.236 \mathrm{E}$ ) and Busingiro (GPS $01^{\circ} 44.090 \mathrm{~N}$, $031^{\circ} 26.855 \mathrm{E}$ ) were located over $10 \mathrm{~km}$ away inland with an altitude of $1295 \mathrm{~m}$ on average above sea level. This purposeful selection aimed to represent the current control landscape of preventive chemotherapy for schistosomiasis across high- and low-endemic settings and capture an altitudinal range where malaria transmission was suspected to vary.

\section{Sample collection and POC diagnosis of malaria}

After obtaining written informed consent and verbal assent, a pre-target enrolment of 60 children per school, of equal gender, randomly recruited from classes primary 1 to 3 , were assessed for study eligibility and requested to provide two stool samples on consecutive days, a single urine sample and a finger-prick blood sample. Pointof-care diagnosis of malaria was made according to an RDT (SD Bioline Malaria Ag P.f/Pan test, SD Diagnostics, Korea). A single drop of blood was spotted onto filter paper (Whatman $3 \mathrm{MM}$, Whatman International, Maidstone, England), dried at ambient temperature and sealed in a plastic bag with dessicant silica gel to preserve each DBS before transportation to the LSTM. DBS were then stored at $-20{ }^{\circ} \mathrm{C}$ before DNA extraction. Stool samples were filtered through a $212 \mu \mathrm{m}$ metal mesh before $0.5 \mathrm{~g}$ were placed in $1 \mathrm{~mL}$ of $95 \%$ ethanol for the EPF before transfer to the LSTM and subsequent DNA extraction.

\section{Detection of Plasmodium DNA by rtPCR TaqMan ${ }^{\mathrm{TM}}$ assay}

DNA extraction from EPF was conducted according to protocols described by Al-Shehri et al. following standard 
methods [33]. For DBS, DNA was extracted using Chelex Resin $\left(\right.$ Chelex ${ }^{\circledR} 100$ sodium form $50-100$ mesh dry, No 11139-85-8, Sigma) [34]. Extracted DNA was quantified and then analysed using a TaqMan $^{\text {TM }}$ genus-specific probe targeting the ribosomal 18S DNA gene [35]. In a total of $25 \mu \mathrm{L}$ in each reaction, consisting of $12.5 \mu \mathrm{L}$ IQ supermix, $5 \mu \mathrm{L}$ of DNA template, specific forward primer, Plasmo-2 $\mathrm{R}$ primer, generic Plasmo-probe, and the reaction volume was completed with nuclease-free $\mathrm{H}_{2} \mathrm{O}$ (Sterile, RNase and DNase Free, 3098-2ML, UK). Extracted DNA-DBS and DNA-EPF for each school were run on different plates, included a number of controls: extraction of TE (10 mM Tris- $\mathrm{HCl}$ [pH 8], 1 mM EDTA) as a negative control, and four positive controls, using DNA extracted from reference P. falciparum, Plasmodium vivax, Plasmodium ovale or Plasmodium malariae infections as provided by the clinical diagnostic laboratory at LSTM. A $10 \%$ selection of experimental results were repeated to ensure assay reproducibility. DNATaqMan $^{\text {TM }}$ assays were performed in a Chromo-4 with Opticon monitor Version 3.1. (Biorad, Hemel Hempstead, UK) and thermal cycling conditions of an initial denaturation of $3 \mathrm{~min}$ at $95{ }^{\circ} \mathrm{C}$, followed by 50 cycles of $15 \mathrm{~s}$ at $95^{\circ} \mathrm{C}, 20 \mathrm{~s}$ at $60^{\circ} \mathrm{C}$ and $15 \mathrm{~s}$ at $72^{\circ} \mathrm{C}$. Infected children were identified according to $C_{t}$ values: either positive $\left(10>C_{t} \leq 45\right)$ or negative $\left(C_{t}>45\right)$.

\section{Antiparasitic treatments offered}

Each child was examined by the project nurse and offered praziquantel $(40 \mathrm{mg} / \mathrm{Kg}$, Merck KGaA, Darmstadt, Germany) and albendazole (400 mg, GSK, Brentford, UK) irrespective of their infection status, although children observed with a positive malaria RDT were each offered a take-home, 3-day course of artemether-lumefantrine (Coartem ${ }^{\circledR}$ Lonart; Cipla, Mumbai, India) treatment with the first and third treatment administrations overseen by the project nurse. The Ugandan Council for Science and Technology and the Liverpool School of Tropical Medicine granted approvals for this study.

\section{Statistical analysis}

Statistical and regression analysis was performed using Minitab Ltd ${ }^{\circledR}$ (Brandon Court, Unit E1-E2 Coventry CV3 2TE UK), calculating prevalence, sensitivity, specificity, positive predictive value (PPV) and negative predictive value (NPV) of each of the diagnostic methods.

\section{Results}

A total of 271 children were initially screened; $247 / 271$ (91.1\%) met the inclusion criteria of sample provision and obtaining verbal assent, were enrolled with mean age of 6.8 years (95\% CI 6.6-6.9), with males accounting for
124/247 (50.2\%), and females 123/247 (49.7\%). Of 247 school-aged children that tested for malaria infection by RDTs using malaria Ag P.f/Pan test, 138 (55.8\%; 95\% CI 49.6-61.9) were positive for P. falciparum (PfHRP-2-detecting RDTs), and 45 samples (18.2\%; 95\% CI 13.9-23.5) were positive for Plasmodium species (PfHRP-II and pan-pLDH test lines). A singleplex rtPCR-based assay for DBS revealed that 198 (80.1\%, 95\% CI 74.7-84.6) children were positive for Plasmodium DNA whereas a singleplex rtPCR-based assay for EPF revealed that 158 (63.9\%; 95\% CI 57.8-69.7) children were positive, (Table 1).

Although absolute values differed, the trends of Plasmodium prevalence across the three diagnostic methods by "Low-High Altitude" and "distance from Lake Albert" were similar. A positive result by any test increased significantly relative to distance from the lake ( $p<0.001$ for all three diagnostic tools) (Fig. 1). The highest prevalence of malaria infection was by DBS analysis of $95.9 \%$ (95\% CI 86.2-98.8) at Busingiro and, for EPF, 91.8\% (95\% CI 80.8-96.7) at Biiso. At low altitudes and the shoreline schools of Walakuba and Runga, prevalence by RDT was 32.5\% (95\% CI 20.4-47.4) and 58.0\% (95\% CI 44.2-70.6), by rtPCR for EPF was $34.8 \%$ (95\% CI 22.4-49.8) and $38.0 \%$ (95\% CI $25.8-51.8$ ), and for DBS was $76.7 \%$ (95\% CI 62.2-86.8) and 84.0\% (95\% CI 71.4-91.6). In Bugoigo school, the prevalence of malaria by rtPCR from EPF appeared raised, 76.7\% (95\% CI 64.2-85.9), upon comparison to the other two diagnostic tools.

The relationship between $C_{t}$ value of rtPCRbased assays for DBS and $C_{t}$ value for EPF was DBS $\left(C_{t}\right)=26.93+0.1763$ EPF $\left(C_{t}\right)$ and was statistically significant $(p=0.01)$, with $\mathrm{R}$-squared $4.14 \%(p<0.005)$. The positive correlation as shown $\mathrm{r}=0.2$ (Fig. 2), indicating that when EPF $\left(C_{t}\right)$ increased, so did the DBS $\left(C_{t}\right)$ $(p<0.05)$, although the magnitude of this change was not substantive. Using RDT results as convenient field-based comparison, the diagnostic score tabulations are presented (Table 2).

\section{Discussion}

In the present study, amplification of Plasmodium DNA from non-invasive EPF and invasive DBS sampling has shown that 158 (63.9\%; 95\% CI 57.8-69.7) and 198 (80.1\%; 95\% CI 74.7-84.6) of 247 children tested positive for infection (Table 1). As might be expected given the greater sensitivity of rtPCR methods based in the laboratory $[7,36,37]$, the prevalence estimated by either EPF or DBS was higher than that by RDTs where 138 children (55.8\%; 95\% CI 49.6-61.9) were judged infected. Using the RDT, inspecting lactate dehydrogenase (pLDH) reactions, 45 infected cases (18.2\%; 95\% CI 13.9-23.5) of pan-Plasmodium spp. co-infections 
Table 1 Prevalence and performance of diagnostic tests for detection of Plasmodium infection in school-aged children

\begin{tabular}{|c|c|c|c|c|c|c|}
\hline School name & $\begin{array}{l}\text { Walukuba }(n=43) \\
n(\%)\end{array}$ & $\begin{array}{l}\text { Runga }(n=50) \\
n(\%)\end{array}$ & $\begin{array}{l}\text { Bugoigo }(n=56) \\
n(\%)\end{array}$ & $\begin{array}{l}\text { Biiso }(n=49) \\
n(\%)\end{array}$ & $\begin{array}{l}\text { Busingiro }(n=49) \\
n(\%)\end{array}$ & $\begin{array}{l}\text { Total }(n=247) \\
n(\%)\end{array}$ \\
\hline \multicolumn{7}{|l|}{ Prevalence } \\
\hline \multicolumn{7}{|c|}{ Rapid diagnostic test ${ }^{\mathrm{a}}$} \\
\hline Negative & $29(67.4)$ & $21(42.0)$ & $26(46.4)$ & $16(32.6)$ & $17(34.6)$ & $109(44.1)$ \\
\hline Positive & $14(32.5)$ & $29(58.0)$ & $30(53.5)$ & $33(67.3)$ & $32(65.3)$ & $138(55.8)$ \\
\hline $95 \% \mathrm{Cl}$ & {$[20.4-47.4]$} & {$[44.2-70.6]$} & {$[40.7-65.9]$} & {$[53.3-78.7]$} & {$[51.3-77.0]$} & [49.6-61.9] \\
\hline \multicolumn{7}{|c|}{ rtPCR-based assays for DBS ${ }^{b}$} \\
\hline Negative & $10(23.2)$ & $8(16.0)$ & $24(42.8)$ & $5(10.2)$ & $2(4.0)$ & 49 (19.8) \\
\hline Positive & $33(76.7)$ & $42(84.0)$ & $32(57.1)$ & $44(89.8)$ & 47 (95.9) & $198(80.1)$ \\
\hline $95 \% \mathrm{Cl}$ & {$[62.2-86.8]$} & {$[71.4-91.6]$} & {$[44.1-69.2]$} & {$[78.2-95.5]$} & {$[86.2-98.8]$} & {$[74.7-84.6]$} \\
\hline \multicolumn{7}{|c|}{ rtPCR-based assays for EPF ${ }^{c}$} \\
\hline Negative & $28(65.1)$ & $31(62.0)$ & $13(23.2)$ & $4(8.1)$ & $13(26.5)$ & $89(36.0)$ \\
\hline Positive & $15(34.8)$ & $19(38.0)$ & $43(76.7)$ & $45(91.8)$ & $36(73.4)$ & $158(63.9)$ \\
\hline $95 \% \mathrm{Cl}$ & {$[22.4-49.8]$} & {$[25.8-51.8]$} & {$[64.2-85.9]$} & {$[80.8-96.7]$} & {$[59.7-83.7]$} & {$[57.8-69.7]$} \\
\hline No. of infected & $(n=33)$ & $(n=42)$ & $(n=32)$ & $(n=44)$ & $(n=47)$ & Total $(n=198)$ \\
\hline \multicolumn{7}{|c|}{ Co-infection (SCH, MAL $\left.{ }^{d}\right)$} \\
\hline Negative & $4(12.1)$ & $6(14.2)$ & $21(65.6)$ & $36(81.8)$ & $43(91.4)$ & $110(55.5)$ \\
\hline Positive & $29(87.8)$ & $36(85.7)$ & $11(34.3)$ & $8(18.1)$ & $4(8.5)$ & $88(44.5)$ \\
\hline $95 \% \mathrm{Cl}$ & [72.6-95.1] & [72.1-93.2] & [20.4-51.6] & {$[9.5-31.9]$} & [3.3-19.9] & [37.6-51.4] \\
\hline
\end{tabular}

a Malaria by RDT (SD Bioline Malaria Ag P.f/Pan test, SD Diagnostics, Yongin-si, Gyeonggi-do, Korea)

b A TaqMan-based real-time PCR assay that collectively detected all 4 Plasmodium species from DBS

c A TaqMan-based real-time PCR assay that collectively detected all 4 Plasmodium species from EPF

d Co-infections among schoolchildren with Plasmodium species detected by rtPCR-based assay for DBS and Schistosoma mansoni by Kato-Katz faecal microscopy

were found. The general agreement of infection mean prevalence and prevalence by school for EPF and RDT was satisfactory and would infer that this non-invasive sampling protocol yields very similar school-level information. A further diagnostic evaluation might consider inclusion of point-of-contract microscopy [38, 39], particularly when parasite densities are below RDT detection thresholds [37].

Taking altitude and distance from Lake Albert into account, the highest prevalence of Plasmodium infection by any method was at Busingiro school, where 47 out of 49 pupils (95.9\%; 95\% CI 86.2-98.8) tested positive by DBS sampling (Table 1). In contrast, 73.4\% (95\% CI 65.2-79.8) of the same pupils tested positive by EPF sampling while prevalence by RDT was $65.3 \%$ (95\% CI 51.3-77.0). The highest prevalence by EPF sampling was at Biiso school, and in all but one school (Runga), both DBS and EPF sampling provided higher prevalence of infection that RDTs (Fig. 1). These findings confirm those by Jirků et al. [25] in that Plasmodium DNA shed at detectable levels by rtPCR can be readily found within faecal material.

Unlike in previous studies where $P$. falciparum infection and parasite density was negatively associated with rising altitude [40-43], this study found that the highest percentages of Plasmodium DNA were in higher altitude schools (Biiso and Busingiro) (Fig. 2b); in both schools, EPF sampling detected a higher percentage of infection than RDTs. At lower altitudes, the performance of EPF sampling was less predictable against the two other methods. It is worthy to note that egg-patent intestinal schistosomiasis is very common in these three schools [44] and may perhaps confound the detection of Plasmodium DNA. When determining the sensitivity and specificity of rtPCR-based assays; an initial evaluation of cycle threshold $\left(C_{t}\right)$ values showed that there was a positive correlation, although not particularly impressive, between DBS- and EPF-derived samples $(r=0.2)$, with a mean EPF Ct value of 36.3, and a mean DBS Ct value of 33.3, (Fig. 2). When correlating these results to RDTs, rtPCR-based assay of DBS samples showed a greater sensitivity than EPF samples (94.2\% versus $73.1 \%$ ), with rtPCR of DBS samples having a specificity of $37.6 \%$ and a PPV of 65.6\%. In contrast, the specificity of EPF sampling was $47.7 \%$, with a PPV of $63.9 \%$ (Table 2).

It is known that schistosomes immuno-modulate host responses which interplay with Plasmodium parasitaemia, often reducing numbers of Plasmodium within the blood [45]. This may lower the amount of Plasmodium DNA ultimately shed into the bowel but as schistosome 

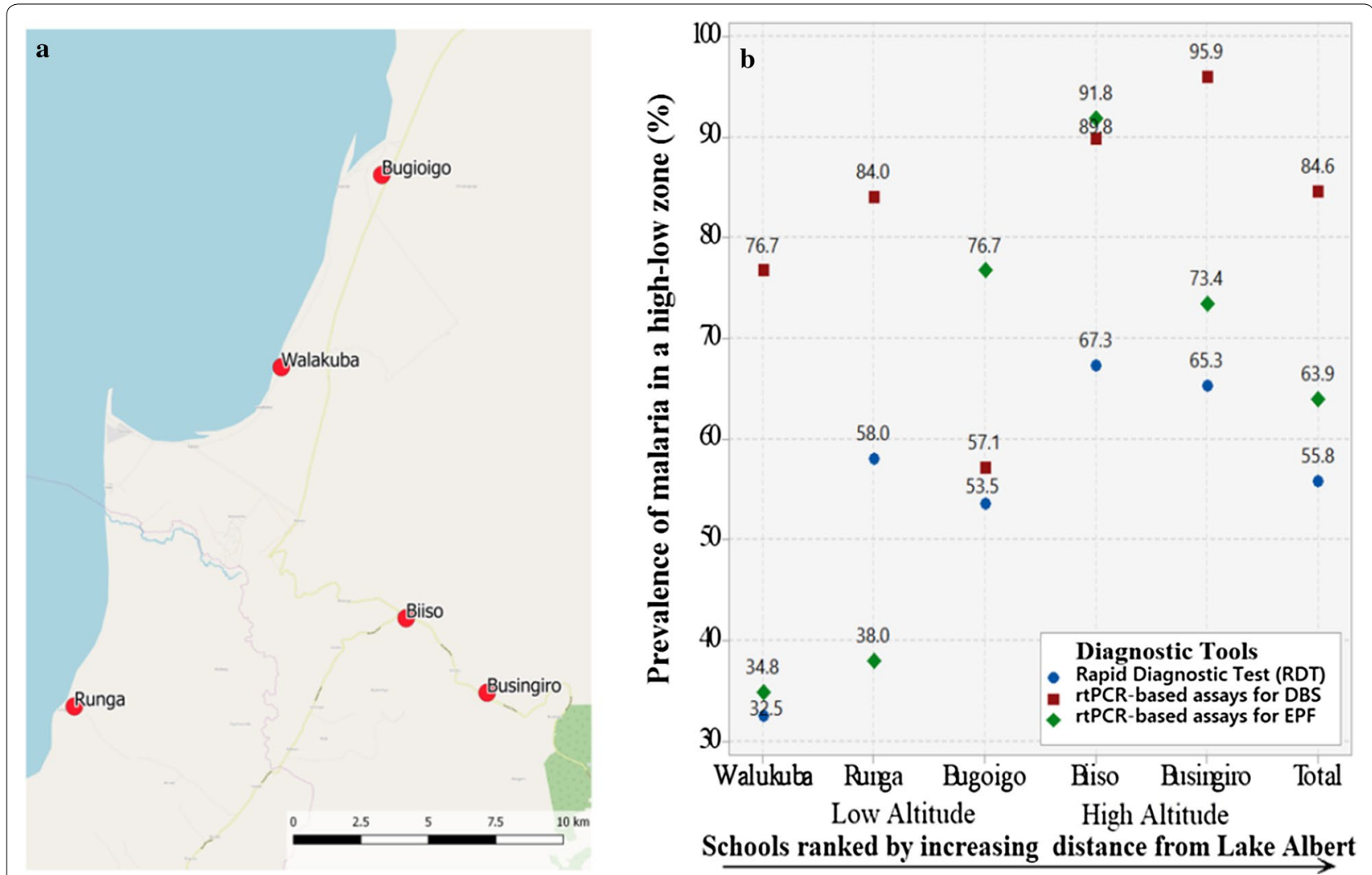

Fig. 1 Location of 5 sampled schools and estimated prevalence of malaria. a Schematic map of the five sampled primary schools in the Lake Albert region, the blue area indicates Lake Albert. The primary schools of Bugoigo, Walakuba and Runga on the lakeshore plain (Low-Altitude), whereas Biiso and Busingiro are located on top of the escarpment (High-Altitude). Once part of Masindi District, the schools are now located within Buliisa District after administrative areas were revised. $\mathbf{b}$ Estimated prevalence of malaria infection by altitude and school distance from the shoreline for each examined diagnostic test

eggs also directly perforate the bowel, and some $11 \%$ of children also had faecal occult blood in stool, thus there may be a more complicated relationship with detected Plasmodium DNA in faecal material than first assumed [25]. It remains to be assessed if this phenomenon also occurs in EPF sampling of non-human primates as intestinal schistosomiasis can naturally occur in these animals [46]. Using rtPCR with Taqman ${ }^{\circledR}$ probes for Schistosoma boosts the diagnostic repertoire for detection of human and zoonotic schistosomiasis $[44,47]$ and could be also applied in non-human primate sampling.

Although faecal sampling has been a routine activity of the national control programme for bilharzia and intestinal worms for over a decade [48, 49], an immediate drawback in the use of EPF sampling is the need for a laboratory setting. Future advances in handheld rtPCR equipment may provide an alternative avenue by which EPF sampling becomes more portable and affordable in field conditions $[7,50,51]$. What is evident from the results of this study is that EPF sampling of Plasmodium infections in school children in this high transmission setting provides information without invasive sampling. Similarly, it has been shown that EPF sampling can shed light on the occurrence of other parasites and pathogens whose nucleic acids may be shed in stool [23]. Such passive collection of stools, or targetted collection for faecal parasites, could aid in developing a general monitoring and surveillance platform. For example, EPF sampling may have future application in evaluating dynamics of malaria in schools where intermittent preventive treatment has been allocated [51]. However, in Ebola-risk areas, due care should be taken in stool collection and processing [52]. With regard to malaria control in Uganda, EPF analysis could contribute to general surveillance of infection in schools [13], encouraging further integrated mapping initiatives with neglected tropical diseases [53], and assessing the future impact of intermittent preventive treatment initiatives [51]. 


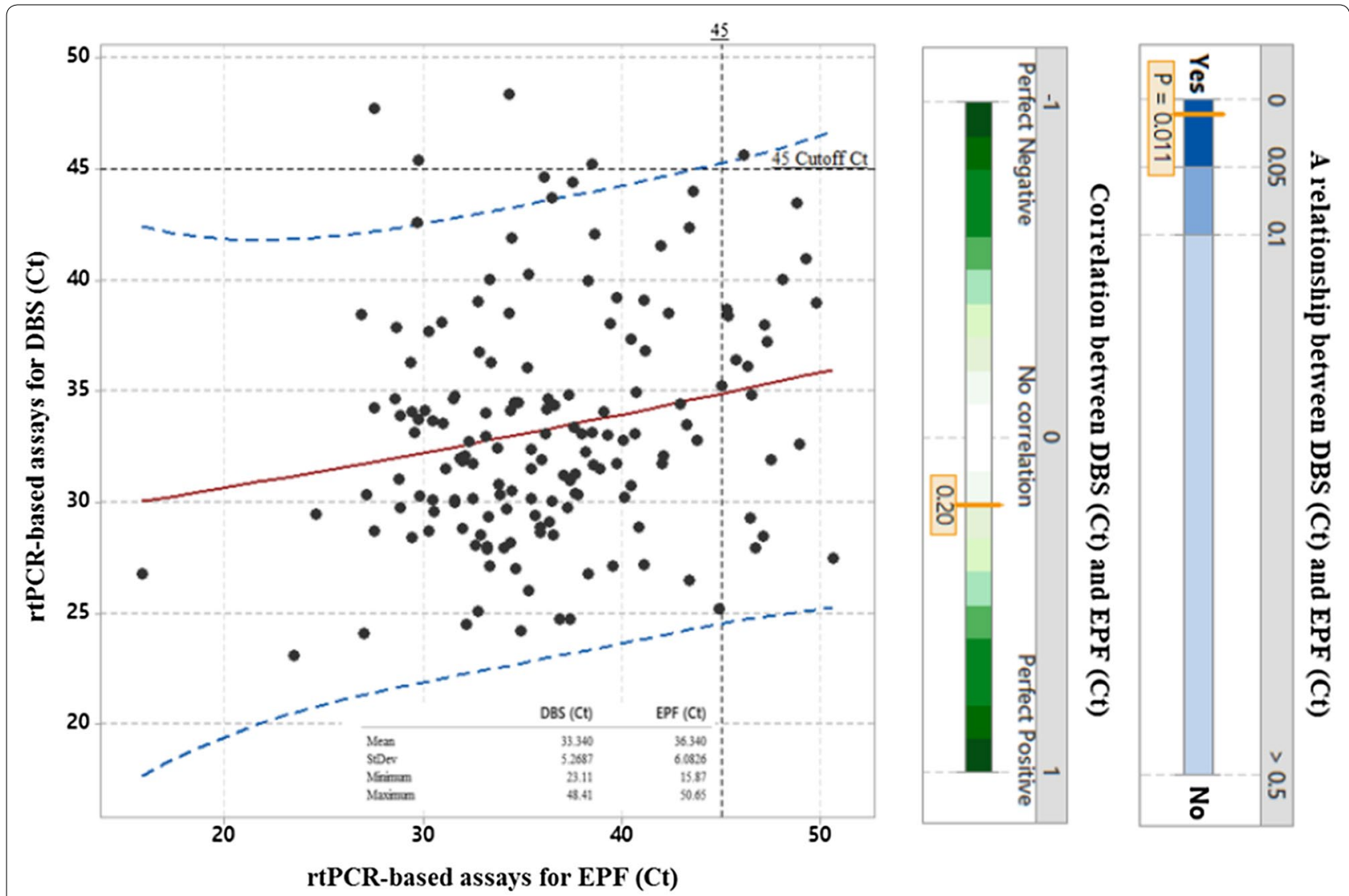

Fig. 2 Showing the regression between rtPCR-based assays for DBS $\left(C_{t}\right)$ and rtPCR-based assays for EPF $\left(C_{t}\right)$ for the singleplex assay to detect generic Plasmodium (18S rDNA gene). The red fitted line shows the predicted value and cross line is the cut off $45 C_{t}$. The blue dashed lines show the $95 \%$ prediction interval. The mean $C_{t}$ value of EPF $\left(C_{t}\right)$ is 36.3 , and DBS $\left(C_{t}\right)$ is 33.3 , and the actual difference between DBS $\left(C_{t}\right)$ and EPD $\left(C_{t}\right)$ is 2.3 $(95 \% \mathrm{Cl} 1.1-3.5)$

Table 2 Empirical estimates of sensitivity (SS), specificity (SP), negative predictive value (NPV) and positive predictive value (PPV), Cohen's kappa for each diagnostic test against Malaria by RDT as 'gold standard'

\begin{tabular}{|c|c|c|c|c|c|c|c|c|}
\hline Assay & Negative (\%) & Positive (\%) & Total (\%) & \multicolumn{2}{|c|}{ Estimate \% (95\% Cls) } & $\begin{array}{l}\text { Diagnostic } \\
\text { accuracy ( } 95 \% \\
\text { Cls) }\end{array}$ & $\begin{array}{l}\text { Diagnostic } \\
\text { odds (95\% } \\
\text { Cls) }\end{array}$ & Cohen's kappa \\
\hline \multicolumn{9}{|c|}{ Rapid diagnostic tests (RDTs) } \\
\hline \multicolumn{9}{|c|}{$\mathrm{rtPCR}$ of $\mathrm{DBS} \mathrm{S}^{\mathrm{a}}$} \\
\hline Negative & $41(83.6)$ & $8(16.3)$ & $49(19.8)$ & Sensitivity & $94.2 \%$ [88.9-97.0] & $69.2 \%[63.2-74.6]$ & $9.7[4.3-22.0]$ & $0.3[0.2-0.4]$ \\
\hline Positive & $68(34.3)$ & $130(65.6)$ & $198(80.1)$ & Specificity & $37.6 \%[29.0-46.9]$ & & & \\
\hline \multirow[t]{2}{*}{ Total (\%) } & $109(44.1)$ & $138(55.8)$ & $247(100.0)$ & PPV & $65.6 \%[58.8-71.9]$ & & & \\
\hline & & & & NPV & $83.6 \%[70.9-91.4]$ & & & \\
\hline \multicolumn{9}{|c|}{ rtPCR of EPFa } \\
\hline Negative & $52(58.4)$ & $37(41.5)$ & $89(36.0)$ & Sensitivity & $73.1 \%[65.2-79.8]$ & $61.9 \%[55.7-67.7]$ & $2.4[1.4-4.2]$ & $0.2[0.1-0.3]$ \\
\hline Positive & $57(36.0)$ & $101(63.9)$ & $158(63.9)$ & Specificity & $47.7 \%[38.5-57.0]$ & & & \\
\hline \multirow[t]{2}{*}{ Total (\%) } & $109(44.1)$ & $138(55.8)$ & $247(100.0)$ & PPV & $63.9 \%[56.1-71.0]$ & & & \\
\hline & & & & NPV & $58.4 \%[48.0-68.1]$ & & & \\
\hline
\end{tabular}

a rtPCR-based assays based on detecting a region of the Plasmodium 18S DNA gene that is conserved across all five species $P$. falciparum, P. vivax, P. ovale and $P$. malariae 


\section{Conclusion}

Examination of EPF by rtPCR analysis in this high transmission setting offers an attractive non-invasive sampling strategy for detection of Plasmodium DNA in school children; prevalence of infection by school was in close agreement with that obtained from POCRDTs using finger prick blood. In future, using EPF and rtPCR analysis could be a powerful disease surveillance platform, able to synergize with helminth control programmes and likely prove useful in passive surveillance of infections within low transmission settings.

\section{Abbreviations \\ Cl: confidence interval; DBS: dried blood spot; EPF: ethanol preserved faeces; RDT: rapid diagnostic tests; rtPCR: real-time polymerase chain reaction.}

\section{Authors' contributions}

Authors contributions were: HAS, AC, JA, EJLaC, BJP, ADA \& JRS performed laboratory DNA investigations while fieldwork in Uganda was undertaken by HAS, JA, MAd, MAr, AA, NBK and JRS. All authors contributed to the initial draft of the manuscript and assented on the final version submitted for consent for publication. All authors read and approved the final manuscript.

\footnotetext{
Author details

${ }^{1}$ Department of Tropical Disease Biology, Liverpool School of Tropical Medicine, Liverpool L3 5QA, UK. ${ }^{2}$ Ministry of Health, Asir District, Abha, Kingdom of Saudi Arabia. ${ }^{3}$ Wellcome Centre for Integrative Parasitology, University of Glasgow, Sir Graeme Davies Building, 120 University Place, Glasgow G12 8TA, UK. ${ }^{4}$ Vector Control Division, Ministry of Health, Kampala, Uganda. ${ }^{5}$ Department of Biological Science, Faculty of Science and Humanities, Shaqra University, Ad-Dawadimi, Saudi Arabia.
}

\section{Acknowledgements}

We thank the children and teachers who took part in this survey; to the VCD field team stationed at Bugoigo Camp for their help during fieldwork. HAS would like to thank Jaco Verweij for his advice and sharing technical skill on diagnostic assays and methods.

\section{Competing interests}

The authors declare they have no competing interests.

\section{Availability of data and materials}

Data sets are available upon request to the corresponding author.

\section{Consent for publication}

Not applicable.

\section{Ethics approval and consent to participate}

The Ugandan Council for Science and Technology and the Liverpool School of Tropical Medicine granted approval for this study. Written informed consent was obtained from the headteacher and guardians of each child.

\section{Funding}

HAS is in receipt of Ph.D. training scholarship from Kingdom of Saudi Arabia, Ministry of Health. The research was sponsored with internal funds within Ministry of Health Uganda and Liverpool School of Tropical Medicine.

\section{Publisher's Note}

Springer Nature remains neutral with regard to jurisdictional claims in published maps and institutional affiliations.

Received: 5 January 2019 Accepted: 26 March 2019

Published online: 01 April 2019

\section{References}

1. WHO. World malaria report. Geneva: World Health Organization; 2018. http://apps.who.int/iris/bitstream/handle/10665/252038/9789241511 711-eng.pdf? sequence=1. Accessed 3 Dec 2018 .

2. Christiansen-Jucht C, Parham PE, Saddler A, Koella JC, Basáñez M-G. Temperature during larval development and adult maintenance influences the survival of Anopheles gambiae ss. Parasit Vectors. 2014;7:489.

3. WHO. T3: test. Treat. Track. Scaling up diagnostic testing, treatment and surveillance for malaria. Geneva: World Health Organization; 2012. \http://www.who.int/malaria/publications/atoz/t3_brochure/en/. Accessed 12 Nov 2018

4. Carneiro I, Roca-Feltrer A, Griffin JT, Smith L, Tanner M, Schellenberg JA, et al. Age-patterns of malaria vary with severity, transmission intensity and seasonality in sub-Saharan Africa: a systematic review and pooled analysis. PLoS ONE. 2010;5:e8988.

5. Nmadu P, Peter E, Alexander P, Koggie A, Maikenti J. The prevalence of malaria in children between the ages 2-15 visiting Gwarinpa General Hospital life-camp, Abuja, Nigeria. J Health Sci. 2015;5:47-51.

6. Roberts $D$, Matthews $G$. Risk factors of malaria in children under the age of five years old in Uganda. Malar J. 2016;15:246.

7. Britton S, Cheng Q, McCarthy JS. Novel molecular diagnostic tools for malaria elimination: a review of options from the point of view of high-throughput and applicability in resource limited settings. Malar J. 2016;15:88

8. Golassa L, Enweji N, Erko B, Aseffa A, Swedberg G. Detection of a substantial number of sub-microscopic Plasmodium falciparum infections by polymerase chain reaction: a potential threat to malaria control and diagnosis in Ethiopia. Malar J. 2013;12:352.

9. Bousema T, Okell L, Felger I, Drakeley C. Asymptomatic malaria infections: detectability, transmissibility and public health relevance. Nat Rev Microbiol. 2014;12:833-40.

10. Hofmann NE, Gruenberg M, Nate E, Ura A, Rodriguez-Rodriguez D, Salib $M$, et al. Assessment of ultra-sensitive malaria diagnosis versus standard molecular diagnostics for malaria elimination: an in-depth molecular community cross-sectional study. Lancet Infect Dis. 2018;18:1108-16.

11. Buppan P, Putaporntip C, Pattanawong U, Seethamchai S, Jongwutiwes S. Comparative detection of Plasmodium vivax and Plasmodium falciparum DNA in saliva and urine samples from symptomatic malaria patients in a low endemic area. Malar J. 2010;9:72.

12. Lloyd YM, Esemu LF, Antallan J, Thomas B, Yunga ST, Obase B, et al. PCRbased detection of Plasmodium falciparum in saliva using mitochondrial cox3 and varATS primers. Trop Med Health. 2018;46:22.

13. Talisuna AO, Noor AM, Okui AP, Snow RW. The past, present and future use of epidemiological intelligence to plan malaria vector control and parasite prevention in Uganda. Malar J. 2015;14:158.

14. Stensgaard AS, Vounatsou P, Onapa AW, Simonsen PE, Pedersen EM, Rahbek C, et al. Bayesian geostatistical modelling of malaria and lymphatic filariasis infections in Uganda: predictors of risk and geographical patterns of co-endemicity. Malar J. 2011;10:298.

15. Al-Shehri H, Stanton MC, LaCourse JE, Atuhaire A, Arinaitwe M, Wamboko A, et al. An extensive burden of giardiasis associated with intestinal schistosomiasis and anaemia in school children on the shoreline of Lake Albert, Uganda. Trans R Soc Trop Med Hyg. 2016;110:597-603.

16. Kabatereine NB, Tukahebwa E, Kazibwe F, Namwangye H, Zaramba S, Brooker S, et al. Progress towards countrywide control of schistosomiasis and soil-transmitted helminthiasis in Uganda. Trans R Soc Trop Med Hyg. 2006;100:208-15.

17. Koukounari A, Fenwick A, Whawell S, Kabatereine NB, Kazibwe F, Tukahebwa EM, et al. Morbidity indicators of Schistosoma mansoni: relationship between infection and anemia in Ugandan schoolchildren before and after praziquantel and albendazole chemotherapy. Am J Trop Med Hyg. 2006;75:278-86.

18. Betson M, Clifford S, Stanton M, Kabatereine NB, Stothard JR. Emergence of nonfalciparum Plasmodium infection despite regular artemisinin combination therapy in an 18-month longitudinal study of Ugandan children and their mothers. J Infect Dis. 2018;217:1099-109.

19. Betson M, Sousa-Figueiredo JC, Atuhaire A, Arinaitwe M, Adriko M, Mwesigwa G, et al. Detection of persistent Plasmodium spp. infections in Ugandan children after artemether-lumefantrine treatment. Parasitology. 2014;141:1880-90. 
20. Sousa-Figueiredo JC, Oguttu D, Adriko M, Besigye F, Nankasi A, Arinaitwe $M$, et al. Investigating portable fluorescent microscopy (CyScope $\left.{ }^{\circledR}\right)$ as an alternative rapid diagnostic test for malaria in children and women of child-bearing age. Malar J. 2010;9:245.

21. Oguike MC, Betson M, Burke M, Nolder D, Stothard JR, Kleinschmidt I, et al. Plasmodium ovale curtisi and Plasmodium ovale wallikeri circulate simultaneously in African communities. Int J Parasitol. 2011:41:677-83.

22. UBoS. Uganda Malaria Indicator Survey 2014-15 Kampala, Uganda, and Rockville, Maryland, USA: UBOS and ICF International; 2015. https://dhspr ogram.com/pubs/pdf/MIS21/MIS21.pdf.Accessed 24 Oct 2018.

23. Cunningham LJ, Odoom J, Pratt D, Boatemaa L, Asante-Ntim N, Attiku K, et al. Expanding molecular diagnostics of helminthiasis: piloting use of the GPLN platform for surveillance of soil transmitted helminthiasis and schistosomiasis in Ghana. PLos Negl Trop Dis. 2018;12:e0006129.

24. Sturrock HJW, Gething PW, Ashton RA, Kolaczinski JH, Kabatereine NB, Brooker S. Planning schistosomiasis control: investigation of alternative sampling strategies for Schistosoma mansoni to target mass drug administration of praziquantel in East Africa. Int Health. 2011;3:165-75.

25. Jirků M, Pomajbíková K, Petrželková KJ, Hůzová Z, Modrý D, Lukeš J. Detection of Plasmodium spp. in human feces. Emerg Infect Dis, 2012;18:634.

26. Abkallo HM, Liu WM, Hokama S, Ferreira PE, Nakazawa S, Maeno Y, et al. DNA from pre-erythrocytic stage malaria parasites is detectable by PCR in the faeces and blood of hosts. Int J Parasitol. 2014;44:467-73.

27. Keita AK, Fenollar F, Socolovschi C, Ratmanov P, Bassene H, Sokhna C, et al. The detection of vector-borne-disease-related DNA in human stool paves the way to large epidemiological studies. Eur J Epidemiol. 2015;30:1021-6.

28. Boundenga L, Ollomo B, Rougeron V, Mouele LY, Mve-Ondo B, DelicatLoembet LM, et al. Diversity of malaria parasites in great apes in Gabon. Malar J. 2015;14:111.

29. Kaiser M, Löwa A, Ulrich M, Ellerbrok H, Goffe AS, Blasse A, et al. Wild chimpanzees infected with 5 Plasmodium species. Emerg Infect Dis. 2010;16:1956.

30. Liu W, Li Y, Learn GH, Rudicell RS, Robertson JD, Keele BF, et al. Origin of the human malaria parasite Plasmodium falciparum in gorillas. Nature. 2010;467:420.

31. Loy DE, Liu W, Li Y, Learn GH, Plenderleith LJ, Sundararaman SA, et al. Out of Africa: origins and evolution of the human malaria parasites Plasmodium falciparum and Plasmodium vivax. Int J Parasitol. 2017:47:87-97.

32. Kabatereine NB, Brooker S, Koukounari A, Kazibwe F, Tukahebwa EM, Fleming FM, et al. Impact of a national helminth control programme on infection and morbidity in Ugandan schoolchildren. Bull World Health Organ. 2007;85:91-9.

33. Verweij JJ, Blangé RA, Templeton K, Schinkel J, Brienen EA, van Rooyen MA, et al. Simultaneous detection of Entamoeba histolytica, Giardia lamblia, and Cryptosporidium parvum in fecal samples by using multiplex real-time PCR. J Clin Microbiol. 2004;42:1220-3.

34. Strøm GE, Tellevik MG, Hanevik K, Langeland N, Blomberg B. Comparison of four methods for extracting DNA from dried blood on filter paper for PCR targeting the mitochondrial Plasmodium genome. Trans R Soc Trop Med Hyg. 2014;108:488-94.

35. Shokoples SE, Ndao M, Kowalewska-Grochowska K, Yanow SK. Multiplexed real-time PCR assay for discrimination of Plasmodium species with improved sensitivity for mixed infections. J Clin Microbiol. 2009;47:975-80.

36. Doctor SM, Liu Y, Whitesell A, Thwai KL, Taylor SM, Janko M, et al. Malaria surveillance in the Democratic Republic of the Congo: comparison of microscopy, PCR, and rapid diagnostic test. Diagn Microbiol Infect Dis 2016:85:16-8.
37. Fancony C, Sebastiao YV, Pires JE, Gamboa D, Nery SV. Performance of microscopy and RDTs in the context of a malaria prevalence survey in Angola: a comparison using PCR as the gold standard. Malar J. 2013;12:284.

38. Coulibaly JT, Ouattara M, Keiser J, Bonfoh B, N'Goran EK, Andrews JR, et al. Evaluation of malaria diagnoses using a handheld light microscope in a community-based setting in rural Cote d'Ivoire. Am J Trop Med Hyg. 2016;95:831-4

39. Stothard JR, Nabatte B, Sousa-Figueiredo JC, Kabatereine NB. Towards malaria microscopy at the point-of-contact: an assessment of the diagnostic performance of the Newton Nm1 microscope in Uganda. Parasitology. 2014;141:1819-25.

40. Drakeley CJ, Carneiro I, Reyburn H, Malima R, Lusingu JP, Cox J, et al. Altitude-dependent and-independent variations in Plasmodium falciparum prevalence in northeastern Tanzania. J Infect Dis. 2005;191:1589-98.

41. Chandler Cl, Drakeley CJ, Reyburn H, Carneiro I. The effect of altitude on parasite density case definitions for malaria in northeastern Tanzania. Trop Med Int Health. 2006;11:1178-84.

42. Pothin E, Ferguson NM, Drakeley CJ, Ghani AC. Estimating malaria transmission intensity from Plasmodium falciparum serological data using antibody density models. Malar J. 2016;15:79.

43. Omondi CJ, Onguru D, Kamau L, Nanyingi M, Ongamo G, Estambale B. Perennial transmission of malaria in the low altitude areas of Baringo County, Kenya. Malar J. 2017;16:257.

44. Al-Shehri H, Koukounari A, Stanton MC, Adriko M, Arinaitwe M, Atuhaire A, et al. Surveillance of intestinal schistosomiasis during control: a comparison of four diagnostic tests across five Ugandan primary schools in the Lake Albert region. Parasitology. 2018;145:1715-22.

45. Wilson S, Dunne DW. Advances in our understanding of the epidemiology of Plasmodium and schistosome infection: informing coinfection studies. Curr Opin HIVAIDS. 2012;7:225-30

46. Standley CJ, Mugisha L, Dobson AP, Stothard JR. Zoonotic schistosomiasis in non-human primates: past, present and future activities at the humanwildlife interface in Africa. J Helminthol. 2012;86:131-40.

47. Standley CJ, Mugisha L, Verweij JJ, Adriko M, Arinaitwe M, Rowell C, et al. Confirmed infection with intestinal schistosomiasis in semi-captive wildborn chimpanzees on Ngamba Island, Uganda. Vector-Borne Zoonotic Dis. 2011;11:169-76.

48. Adriko M, Tinkitina B, Arinaitwe M, Kabatereine NB, Nanyunja M, Tukahebwa EM. Impact of a national deworming campaign on the prevalence of soil-transmitted helminthiasis in Uganda (2004-2016): implications for national control programs. PLos Negl Trop Dis. 2018;12:e0006520.

49. Ahrberg CD, Ilic BR, Manz A, Neužil P. Handheld real-time PCR device. Lab Chip. 2016;16:586-92.

50. Li T-J, Chang C-M, Chang P-Y, Chuang Y-C, Huang C-C, Su W-C, et al. Handheld energy-efficient magneto-optical real-time quantitative PCR device for target DNA enrichment and quantification. NPG Asia Mater. 2016;8:e277.

51. Staedke SG, Maiteki-Sebuguzi C, Rehman AM, Kigozi SP, Gonahasa S, Okiring J, et al. Assessment of community-level effects of intermittent preventive treatment for malaria in schoolchildren in Jinja, Uganda (START-IPT trial): a cluster-randomised trial. Lancet Glob Health. 2018;6:E668-79.

52. Vetter P, Fischer WA, Schibler M, Jacobs M, Bausch DG, Kaiser L. Ebola Virus shedding and transmission: review of current evidence. J Infect Dis. 2016;214:S177-84.

53. Kabatereine NB, Standley CJ, Sousa-Figueiredo JC, Fleming FM, Stothard $J R$, Talisuna A, et al. Integrated prevalence mapping of schistosomiasis, soil-transmitted helminthiasis and malaria in lakeside and island communities in Lake Victoria, Uganda. Parasit Vectors. 2011;4:232. 